\title{
PRODUÇÃO DE MUDAS DE GOIABEIRA (Psidium guajava L.), INOCULADAS COM O FUNGO MICORRÍZICO ARBUSCULAR Glomus clarum, EM SUBSTRATO AGRO-INDUSTRIAL ${ }^{1}$
}

\author{
JOLIMAR ANTONIO SCHIAVO² \& MARCO ANTONIO MARTINS ${ }^{3}$
}

\begin{abstract}
RESUMO - Conduziu-se um experimento em casa de vegetação, com o objetivo de avaliar o crescimento de mudas de goiabeira (Psidium guajava L.), produzidas em blocos prensados, confeccionados com resíduos agro-industriais, e inoculadas com o fungo micorrízico arbuscular (FMA) Glomus clarum Nicolson \& Schenck. O delineamento experimental utilizado foi o inteiramente casualizado, em esquema fatorial 2 × 2, sendo 2 tratamentos microbiológicos: controle e FMA; e 2 sistemas de produção de mudas: blocos prensados (nova metodologia) e tubetes plásticos (tradicional), com 5 repetições. O substrato utilizado para a confecção dos blocos prensados e enchimento dos tubetes foi constituído por uma mistura de bagaço de cana-de-açúcar e torta de filtro (3:1 v/v). O FMA proporcionou aumentos significativos na produção de matéria seca, conteúdo de $\mathrm{N}$ e $\mathrm{P}$ da parte aérea da goiabeira, apenas no sistema de produção das mudas em blocos prensados. Mudas produzidas e inoculadas em blocos prensados mostraram um aumento de $88 \%$ na matéria seca da parte aérea, $82 \%$ e $89 \%$ para os conteúdos de nitrogênio e fósforo da parte aérea, respectivamente, em relação ao tratamento-controle.
\end{abstract}

Termos de indexação: micorrizas, goiaba, tubetes plásticos, blocos prensados.

\section{PRODUCTION OF GUAVA ( Psidium guajava L.) PLANTS INOCULATED WITH ARBUSCULAR MYCORRHIZAL FUNGI Glomus clarum, IN AGRO-INDUSTRIAL SUBSTRATE}

\begin{abstract}
A greenhouse experiment was carried out to evaluate the growth of guava plant seedlings, inoculated with arbuscular mycorrhizal fungi (AMF), Glomus clarum Nicolson \& Schenck, produced in pressed blocks made with agro-industrial residues. The experimental design utilized was a completely randomized in factorial $2 \times 2$, having two microbiological treatments: control and inoculated; two systems of production: pressed blocks (new methodology) and plastic tubes (traditional), with 5 repetitions. The substrate utilized to make the pressed blocks and to fill the plastic tubes was constituted by a mixture of sugarcane bagasse and filter cake (3:1 $\mathrm{v} / \mathrm{v})$. The AMF inoculation led to a significant increase in dry matter yield and nutrients content of shoot plants, only in pressed blocks. Plants produced in pressed blocks, when inoculated with AMF, showed an increase of $88 \%$ in dry matter yield, $82 \%$ of nitrogen content and $89 \%$ of phosphorus content in the plant shoots.
\end{abstract}

Index terms: mycorrhiza, guava, plastic tubes, pressed blocks.

\section{INTRODUÇÃO}

Alguns trabalhos têm demonstrado que a inoculação de fungos micorrízicos arbusculares (FMAs) no sistema de produção de mudas representa um grande potencial para o desenvolvimento de um cultivo racional e eficiente de mudas de boa qualidade de diversas fruteiras (Samarão e Martins, 1999; Soares e Martins, 2000; Martins et al., 2000). As associações micorrízicas são caracterizadas por uma simbiose mutualista entre a raiz e o fungo endomicorrízico que proporciona à planta hospedeira um melhor desenvolvimento devido à maior absorção de nutrientes, principalmente fósforo, maior resistência ao estresse hídrico e transplante. Entretanto, devido à natureza biotrófica desses fungos que crescem e se multiplicam somente na presença de raízes metabolicamente ativas, a grande limitação é a produção em escala comercial de inóculo de FMAs. Outro fator importante para produzir mudas de alta qualidade, é o método de produção. A utilização de recipientes com paredes rígidas para produção de mudas tem mostrado que esses recipientes provocam, pelo pequeno volume de substrato que comportam, deformações no sistema radicular, refletindo no crescimento e desenvolvimento da parte aérea das mudas, as quais persistem no campo (Barroso, 1999; Morgado et al., 2000).

Em alguns países escandinavos, é utilizado com sucesso o sistema de produção de mudas em blocos prensados, confeccionados com resíduos orgânicos. No Brasil, alguns trabalhos têm testado a viabilidade técnica de produção de essências florestais em blocos com substrato prensado (Barroso, 1999; Leles et al., 2000 e Morgado et al., 2000). Espera-se que a produção de mudas nesses blocos, além de permitir a possibilidade da viabilidade técnica de inoculação com FMAs, possa proporcionar uma uniformidade no desenvolvimento das mudas, pois não

1 (Trabalho 102/2001). Recebido: 09/05/2001. Aceito para publicação: 08/02/2002. Parte da dissertação de Mestrado do primeiro autor, apresentada à UENF, Campos (RJ).

2 Estudante de doutorado do curso de pós-graduação em Produção vegetal da UENF, Av. Alberto Lamego 2000, Cep. 28015-620, Campos, RJ. e-mail schiavo@uenf.br.

3 Professor de Microbiologia do Solo, UENF/CCTA, Av. Alberto Lamego 2000, Cep. 28015-620, Campos, RJ. 
havendo limitações de paredes, ocorrerá o desenvolvimento das raízes por todos os lados, sem confinamento ou direcionamento. Portanto, o crescimento ocorrerá de forma natural.

Este trabalho teve como objetivo avaliar a viabilidade técnica de se produzir mudas de goiabeira inoculadas com FMAs em blocos prensados, confeccionados com resíduos agroindustriais (nova metodologia) comparados ao sistema de tubetes plásticos (tradicional), utilizando resíduo agroindustrial como substrato.

\section{MATERIAL E MÉTODOS}

O delineamento experimental utilizado foi o inteiramente casualizado, em esquema fatorial $2 \times 2$, sendo 2 tratamentos microbiológicos: controle e FMA; e 2 tipos de sistemas de produção de mudas: tubetes (tradicional) e blocos prensados (nova metodologia), com 5 repetições. A unidade experimental foi composta por nove plantas no bloco prensado e nove na bandeja de tubetes.

Os blocos prensados foram confeccionados com o substrato umedecido, colocados em fôrma metálica de 40 x 60 x $20 \mathrm{~cm}$ e prensados com prensa hidráulica a $10 \mathrm{kgf} . \mathrm{cm}^{-2}$, a fim de proporcionar agregação do material. Uma tampa foi colocada sobre a fôrma no momento da prensagem, tendo em sua face inferior 96 cones com $1 \mathrm{~cm}$ de altura, destinados a marcar os orifícios a serem plantadas as estacas enraizadas.

Os tubetes utilizados foram de modelo cônico, com seção circular, contendo oito frisos internos longitudinais e eqüidistantes, $190 \mathrm{~mm}$ de altura, $50 \mathrm{~mm}$ de diâmetro interno superior e volume de aproximadamente $250 \mathrm{~cm}^{3}$.

O substrato utilizado para a produção de mudas, nos dois tipos de recipientes, foi constituído por uma mistura de bagaço de cana-de-açúcar, torta de filtro de usina açucareira e vermiculita. Primeiramente, o bagaço de cana e a torta de filtro foram passados em peneira de $2 \mathrm{~mm}$, misturados na proporção 3/1 v/v. Foram adicionados $6 \mathrm{~g} \cdot \mathrm{kg}^{-1}$ de $\mathrm{N}$, tendo como fonte a uréia, com o objetivo de diminuir a relação $\mathrm{C} / \mathrm{N}$. O material foi colocado para compostar por um período de 35 dias, sendo revolvido e umedecido semanalmente. Terminado esse período, o material compostado foi misturado com a vermiculita na proporção 3/1 v/ $\mathrm{v}$, e tratado com brometo de metila, na dosagem de $30 \mathrm{ml} . \mathrm{m}^{-3} \mathrm{de}$ substrato, por 48 horas, para eliminação de patógenos.

$\mathrm{A}$ análise química do substrato mostrou os seguintes resultados: $\mathrm{pH}$ em $\mathrm{H}_{2} \mathrm{O}(1: 2,5)=6,6 ; \mathrm{P}($ Mehlich- 1$)=3540 \mathrm{mg} \cdot \mathrm{dm}^{-}$ 3; $\mathrm{P}\left(\mathrm{H}_{2} 0\right)=73 \mathrm{mg} \cdot \mathrm{dm}^{-3} ; \mathrm{K}=742 \mathrm{mg} \cdot \mathrm{dm}^{-3} ; \mathrm{Ca}=151 \mathrm{mmol} \cdot \mathrm{dm}^{-3} ; \mathrm{Mg}$ $=63 \mathrm{mmol} \cdot \mathrm{dm}^{-3} ; \mathrm{Al}=0,0 \mathrm{mmol} \cdot \mathrm{dm}^{-3} ; \mathrm{H}$ total $=29 \mathrm{mmol} \cdot \mathrm{dm}^{-3} ; \mathrm{Na}$ $=4,9 \mathrm{mmol} \cdot \mathrm{dm}^{-3} ; \mathrm{C}=82,8 \mathrm{~g} \cdot \mathrm{dm}^{-3} \mathrm{e} \mathrm{N}$ total $=12,8 \mathrm{~g} \cdot \mathrm{dm}^{-3}$.

O substrato utilizado para o preparo do inóculo consistiu em uma mistura de solo e areia na proporção de 1:2 (v/v). O substrato foi esterilizado em autoclave, por três vezes, a uma temperatura de $121^{\circ} \mathrm{C}$, por uma hora. $\mathrm{O}$ substrato foi colocado em vasos de cultivo com 51 de capacidade e infectado com uma mistura de solo contendo esporos e raízes colonizadas com o fungo Glomus clarum Nicolson \& Schenk. Como planta hospedeira, foram semeadas sementes de Brachiaria bryzantha. Os vasos foram mantidos em casa de vegetação por um período de quatro meses para a multiplicação do fungo, os quais foram utilizados como inóculo. A inoculação com FMA foi feita no mo- mento da confecção do bloco, na proporção de $10 \%$ do volume do substrato, tendo como inóculo uma mistura de solo, raízes colonizadas e esporos do fungo.

A cultivar de goiaba utilizada no experimento foi a Paluma. Estacas herbáceas de aproximadamente $10 \mathrm{~cm}$ de comprimento, com dois nós e um par de folhas cortadas ao meio, foram colocadas para enraizar em tubetes de $50 \mathrm{~cm}^{3}$ tendo como substrato areia, e utilizando como promotor de enraizamento ácido indolacético, na concentração de $2000 \mathrm{mg} . \mathrm{l}^{-1}$. Essas estacas permaneceram em telado com nebulização intermitente por um período de 45 dias, para que houvesse a emissão de raízes. Terminado esse período, elas foram transferidas para tubetes e blocos prensados, após ser realizado um desbaste a $2 \mathrm{~cm}$ da inserção das raízes. Cada bandeja com dimensões de 60 × $40 \mathrm{~cm}$ apresentou 54 tubetes, e o bloco com as mesmas dimensões apresentou 96 locais a serem plantados. O volume de substrato explorado pelas plantas foi o mesmo em ambos os recipientes $\left(250 \mathrm{~cm}^{3}\right)$.

Duas mudas de cada parcela foram coletadas 60 dias após o plantio nos blocos prensados e nos tubetes. $\mathrm{O}$ sistema radicular foi separado da parte aérea. Após lavagem com água de torneira, subamostras de $2 \mathrm{~cm}$ de comprimento das raízes foram coletadas e conservadas em álcool etílico $50 \% \mathrm{v} / \mathrm{v}$ para posterior determinação da porcentagem de colonização, pelo método da interseção em placas de Petri reticuladas (Giovannetti e Mosse, 1980), após a coloração das raízes com azul de metila.

$\mathrm{O}$ conteúdo de $\mathrm{N}$ e $\mathrm{P}$, na parte aérea, foi determinado depois que as amostras foram desidratadas em estufa de ventilação forçada, a uma temperatura de cerca de $75^{\circ} \mathrm{C}$, por 48 horas (Malavolta et al., 1989). Uma vez desidratado, o material foi pesado para a determinação da matéria seca e, em seguida, as amostras foram moídas em moinho tipo Willey, passadas em peneira de 20 "mesh" e armazenadas em frascos hermeticamente fechados. Após submeter o material vegetal à oxidação pela digestão sulfúrica, foi determinado o fósforo por colorimetria, pelo método do molibdato (Malavolta et al., 1989) e N pelo método de Nessler (Jackson, 1965).

Foram feitas a análise de variância e a comparação de médias, pelo teste de Tukey, a 5\% de nível de significância, para os dados de matéria seca da parte aérea, conteúdo de $\mathrm{N}$ e $\mathrm{P}$ da parte aérea, utilizando o programa computacional SAEG - Sistema de Análises Estatística e Genética (Euclydes,1983).

\section{RESULTADOS E DISCUSSÃO}

A produção de matéria seca, os conteúdos de nitrogênio e fósforo da parte aérea das mudas produzidas nos blocos prensados, inoculados com o FMA, foram significativamente maiores quando comparados ao tratamento bloco prensado sem inoculação, apresentando incrementos de $89 \%, 82 \%$ e $89 \%$, respectivamente (Figura 1). Por outro lado, nas mudas produzidas em tubetes plásticos, a presença do FMA não proporcionou aumentos significativos nas variáveis analisadas.

O sistema de produção de mudas em blocos prensados proporcionou melhores resultados para as variáveis analisadas somente quando se efetuou a inoculação das mudas com o fungo Glomus clarum, observando-se aumentos de 64\%, 45\%, 57\%, para matéria seca da parte aérea, conteúdos de $\mathrm{N}$ e $\mathrm{P}$ da parte aérea, respectivamente, quando comparado ao sistema de pro-

Rev. Bras. Frutic., Jaboticabal - SP, v. 24, n. 2, p. 519-523, agosto 2002 
dução em tubetes (Figura 1).

No presente trabalho, para a produção de um bloco prensado, necessitou-se de 36 litros de substrato, correspondendo a $375 \mathrm{ml}$ por planta, que, após ser prensado a uma força de 10 $\mathrm{kgf} . \mathrm{cm}^{-2}$, apresentou o volume de $250 \mathrm{~cm}^{3}$. No caso dos tubetes, houve o cuidado de se adicionar $375 \mathrm{ml}$ de substrato em cada tubete de $250 \mathrm{~cm}^{3}$ para que as plantas, nos blocos prensados e nos tubetes, pudessem explorar o mesmo volume de substrato. Assim, o menor crescimento verificado nas plantas micorrizadas produzidas em tubetes, possivelmente, pode ser atribuído ao fato de a parede rígida do recipiente provocar alterações fisiológicas nas mudas, provocando menor absorção de água e nutrientes, uma vez que a colonização micorrízica foi equivalente em ambos os sistemas de produção, $41,1 \%$ no sistema tubete plástico e $41,5 \%$ nos blocos prensados. Vários são os fatores físicos ou fisiológicos que restringem o crescimento radicular afetando o crescimento, desenvolvimento e produtividade das plantas. Dentre estes fatores, podem-se destacar a densidade do solo, tamanho de agregados, tamanho dos poros, presença da camada compactada subsuperficial, aeração, temperatura, qualidade da luz, limitações de nutrientes, densidade de raízes e o volume, tamanho e forma do recipiente onde cresce a planta. Trabalhos realizados para verificar o efeito do volume do recipiente no crescimento e desenvolvimento de plantas têm mostrado que a restrição radicular pode diminuir o crescimento das raízes e da parte aérea das plants (Peterson et al.,1991b). Sugere-se que o processo envolvido nessa redução do crescimento inclua a inibição da elongação foliar (Peterson et al., 1991a), fotossíntese (Ismail e Noor, 1996), mudança na partição da matéria seca da planta e absorção de nutrientes (Bar-Tal e Pressman, 1996) e metabolismo hormonal (Peterson et al., 1991a, 1991b).

Leles et al. (2000), em trabalho com três espécies de eucaliptos, produzidas em tubetes e em blocos prensados, verificaram que as características morfológicas das mudas dos blocos prensados foram superiores às dos tubetes, e que, no campo, as plantas originárias de mudas produzidas em blocos prensados apresentaram maior crescimento em altura e diâmetro ao nível do solo, que as de tubetes, ao longo de dez meses de avaliação. Provavelmente, porque as mudas desenvolvidas nestes blocos, possuem os sistemas radiculares completamente livres, sem qualquer parede que os possa direcionar. Entretanto, as espécies não foram inoculadas com FMAs, e o volume foi diferente entre os sistemas de produção, sendo de $50 \mathrm{~cm}^{3}$ nos tubetes e de 250 $\mathrm{cm}^{3}$ nos blocos prensados.

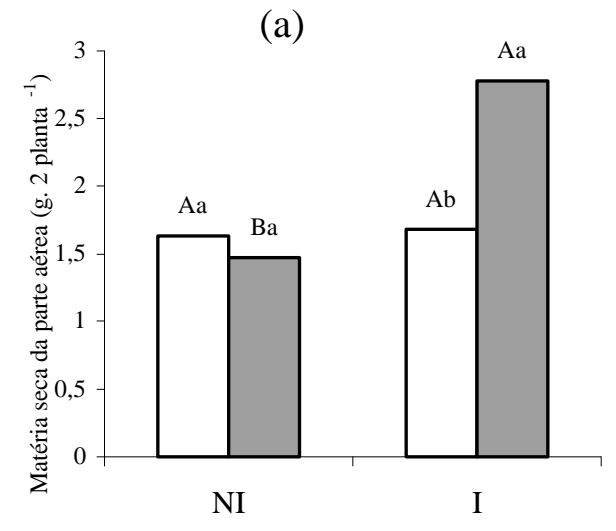

(c)

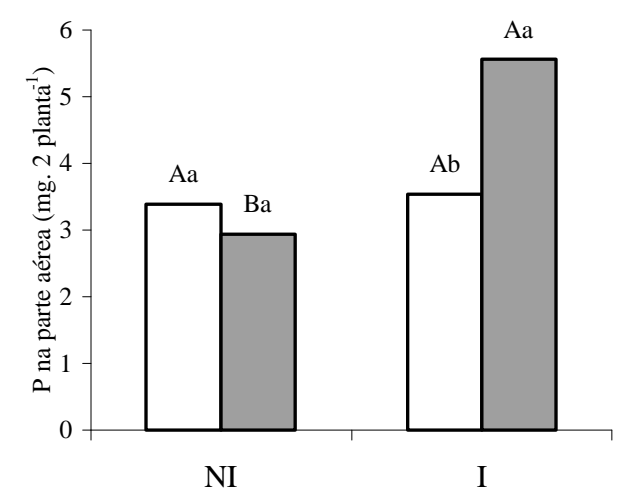

(b)

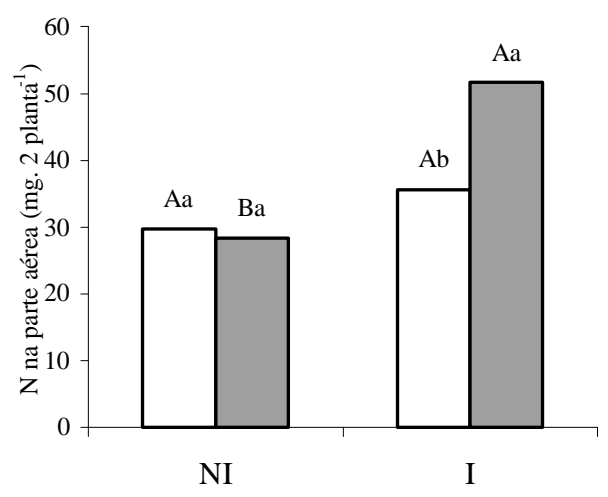

(d)

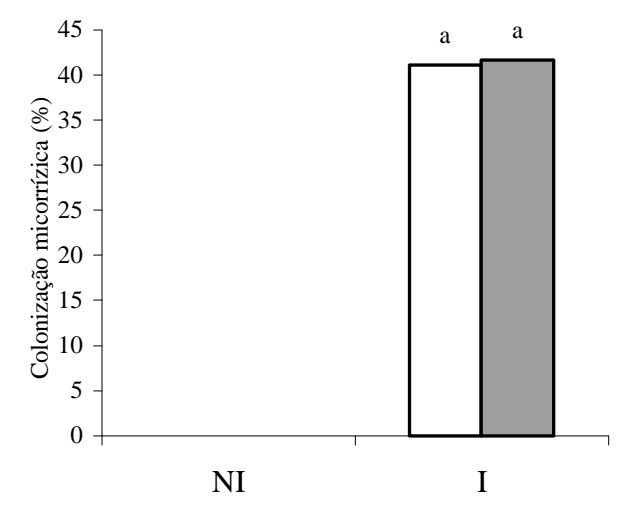

FIGURA 1 - Matéria seca (a), conteúdos de N (b) e P (c) da parte aérea e colonização micorrízica das raízes (d) de mudas de goiabeira (Psidium guajava L.), inoculadas (I) ou não (NI) com o fungo micorrízico arbuscular Glomus clarum, em tubetes plásticos ( $\square$ ) e em blocos prensados $(\square)$. Médias seguidas pela mesma letra minúscula, para recipiente, e maiúscula, para tratamento microbiológico, não diferem entre si, pelo teste de Tukey $(\mathrm{P}<0,05)$. 
Kumaran e Azizah (1995) demonstraram que mudas de goiabeira inoculadas com Glomus mossae e Scutellospora calospora também apresentaram aumento de matéria seca da parte aérea e maior absorção de nutrientes. Os FMAs aumentaram a absorção de nutrientes, principalmente os de baixa mobilidade na solução do solo, como o fósforo (Marschner, 1995), pois a hifa do fungo pode absorver e translocar o fósforo para a planta hospedeira além da zona de depleção em volta das raízes. A resposta à inoculação com FMAs depende da quantidade de $\mathrm{P}$ disponível no solo. A falta de resposta do crescimento das plantas à inoculação com FMAs sob altas doses de $\mathrm{P}$ já foi observada anteriormente (Harley e Smith, 1983). Chandrashekara et al. (1995) constataram que os benefícios dos FMAs para o crescimento das plantas diminui, quando a disponibilidade de fósforo é alta.

No presente trabalho, a inoculação com Glomus clarum proporcionou, nas mudas produzidas em blocos prensados, aumentos significativos nas características avaliadas, mesmo em altas quantidades de $\mathrm{P}$ disponível pelo extrator Mehlich. A análise química do substrato utilizado para a produção das mudas revelou alta quantidade de fósforo disponível pelo extrator Mehlich. Entretanto, foi constatada uma boa taxa de colonização nas raízes das plantas, sendo de 41,09\% nas plantas em tubetes e de $41,65 \%$ nas dos blocos prensados (Figura 1d). Essa colonização pode ser explicada pelo fato de a alta quantidade de fósforo extraída pelo extrator ser superior àquela que é extraída pelas plantas. Entretanto, quando se utilizou água como extrator, a quantidade de fósforo encontrada foi de $73 \mathrm{mg} . \mathrm{dm}^{-3}$ de substrato. Esse valor, provavelmente, estaria mais próximo ao que a planta realmente consegue extrair. Samarão e Martins (1999), em experimento com mudas de goiaba inoculadas com FMAs sob diferentes doses de fósforo, observaram que, mesmo na dose mais alta $\left(50 \mathrm{mg} \cdot \mathrm{dm}^{-3}\right)$, houve uma taxa de colonização de $52 \%$, proporcionando um aumento na produção de matéria seca da parte aérea e no conteúdo de fósforo e potássio da parte aérea. Entretanto, para que os FMAs possam ser aplicados com sucesso em incrementar o desenvolvimento e a produção das culturas mediante seus efeitos na nutrição das plantas e outros benefícios diretos e indiretos, também é necessário considerar outros aspectos, dentre os quais, a adaptação a fatores edáficos e competição com fungos nativos, que podem comprometer a eficiência simbiótica dos FMAs introduzidos na inoculação (Balakrishna et al., 1996).

Os resultados sugerem que a nova metodologia de blocos prensados é recomendável para a produção de mudas de goiabeira, uma vez que o sistema tem como vantagem o maior número de mudas produzidas por área, quando comparado ao sistema tradicional de tubetes, ou seja, 42 mudas a mais para a mesma área. Outro fator de relevância é que o sistema de blocos prensados apresenta a viabilidade técnica de inoculação, além de promover um maior desenvolvimento das mudas.

\section{CONCLUSÕES}

1. A espécie Glomus clarum promoveu o crescimento das mudas de goiabeira, apenas no sistema de blocos prensados.

2. O sistema de blocos prensados mostrou-se eficiente para o crescimento das mudas de goiabeira, provando ser possível utilizá- lo em conjunto com a inoculação com os fungos micorrízicos arbusculares (FMAs).

3. Os resíduos da indústria açucareira (bagaço e torta de filtro de cana de açúcar), inoculados com o FMA, podem ser utilizados como substrato para produção de mudas de goiabeira.

\section{AGRADECIMENTOS}

À Fundação Carlos Chagas Filho de Amparo à Pesquisa do Estado do Rio de Janeiro (FAPERJ), pelo apoio financeiro.

\section{REFERÊNCIAS BIBLIOGRÁFICAS}

BALAKRISHNA, R.; BAGYRAJ, D.J.; MALLESHA, B.C.; REDDY, B. Selection of efficient VA mycorrhizal fungi for papaya. Biol. Agric. Hort., v.13, p.1-6, 1996.

BAR-TAL, A.; E. PRESSMAN. Root restriction and potassium and calcium solution concentrations affect dry-matter production, cation up-take, and blossom-end rot in geenhouse tomato. Journal of the American Society for Horticultural Science, Alexandria, v. 121, p. 649-655, 1996.

BARROSO, D.G. Qualidade de mudas de Eucalyptus camaldulensis e $E$. urophylla produzidas em tubetes e em blocos prensados com diferentes substratos. 71p. Tese (Doutorado em Produção Vegetal) - Universidade Estadual do Norte Fluminense, Campos dos Goytacazes, 1999.

CHANDRASHEKARA, C.P., PATIL, V.C., SREENIVASA, M.N. VA-mycorrhiza mediated $P$ effect on growth and yield of sunflower (Helianthus annuus L.) at different P levels. Plant and Soil , Dordrecht, v.176. p.325-328, 1995.

EUCLYDES, R.F. Sistema para análises estatística e genética (SAEG). DPD/UFV, Vicose: Divisão de Pesquisa e Desenvolvimento, 1983, 74p.

GIOVANNETTI, M.; MOSSE, B. An evalution of techniques for measuring vesicular-arbuscular mycorrhizal infection in roots. New Phytologist, Cambridge, v.84, p.489-500, 1980.

HARLEY, J.L.; SMITH, S.E. Mycorrhizal symbiosis. London: Academic Press, 1983. 483p.

ISMAIL, M.R.; K.M. NOOR. Growth, water relations and physiological processes of starfruit (Averrhoa carambola L.) plants under root growth restriction. Scientia Horticultural, Amsterdam, 66:51-58, 1996.

JACKSON, M.L. Soil chemical analysis. New Jersey: Prentice Hall,. 1965.489p.

KUMARAN, S.; AZIZAH, H. C. Influence of biological soil conditioner on mycorrhizal versus non - mycorrhizal guava seedlings. Tropical Agriculture, St Augustine, v.72, n. 1, p. 39-43, 1995. 
LELES, P.S.S.; CARNEIRO, J.G.A.; BARROSO, D.G.; MORGADO, I.F. Qualidade de mudas de Eucalyptus spp. produzidas em blocos prensados e em tubetes. Revista Árvore, Viçosa, v.24, n.1, p.13-20, 2000.

MALAVOLTA, E.; VITTI, G.C.; OLIVEIRA, S.A.Avaliação do estado nutricional das plantas. Piracicaba: Associação Brasileira para pesquisa da Potassa e do Fosfato, 1989. 201p.

MARSCHNER, H. Mineral nutrition of higher plants. London: Academic Press,. 1995. 889p.

MARTINS, M.A.; GONÇALVES, G.F.; SOARES, A.C.F. Efeito de fungos micorrízicos arbusculares associados a compostos fenólicos, no crescimento de mudas de mamoeiro. Pesquisa Agropecuária Brasileira, Brasília, v.35, n.7, p.1465-1471, 2000.

MORGADO, I.F.; CARNEIRO, J.G.A.; LELES, P.S.S.; BARROSO, D.Q. Nova metodologia de produção de mudas de Eucalyptus grandis W. Hill ex Maiden utilizando resíduos prensados como substrato. Revista Árvore, Viçosa, v.24, n.1, p.27-33, 2000.
PETERSON, T.A.; COHEN, J. D.; BUTA.J. G.; KRIZEK, D. T. Influence of root restriction on tomato: Changes in leaf cell expansion, abscisic acid and indole-3-acetic acid. Plant Physiology 96 (suppl.): 78, 1991a.

PETERSON, T.A.; REINSEL, M.D.; KRIZEK, D.T. Tomato (Lycopersicum esculentum Mill., cv. 'Better Bush') plant response to root restriction. Journal of Experimental Botany, v.42, n.243, p.1233-1240, 1991 b.

SAMARÃO, S.S.; MARTINS, M.A. Influência de fungos micorrízicos arbusculares, associada à aplicação de rutina, no crescimento de mudas de goiabeira (Psidium guajava L.). Revista Brasileira de Fruticultura, Jaboticabal, v.21, n.2, p.196-199, 1999.

SOARES, A.C.F.; MARTINS, M.A. Influência de fungos micorrízicos arbusculares, associada à adição de compostos fenólicos, no crescimento de mudas de maracujazeiro-amarelo (Passiflora edulis f. flavicarpus). Revista Brasileira de Ciências do Solo, Campinas, v.24, n.4, p.731-740, 2000. 